Doi: $\underline{\text { dx.doi.org/10.17921/2525-5320.2016.158-163 }}$

\title{
EXPERIÊNCIAS COM DUAS ALUNAS COM DEFICIÊNCIA NO ENSINO SUPERIOR EM ENFERMAGEM: ANÁLISE DE UM RELATO DOCENTE
}

\author{
Maicon Depieri* - UNOPAR \\ Taísa Grasiela Gomes Liduenha Gonçalves* - UNOPAR \\ Bernadete de Lourdes Streisky Strang* - UNOPAR
}

Palavras-chave: Alunas. Deficiência. Ensino superior. Enfermagem.

\section{INTRODUÇÃO}

De acordo com a Lei de Diretrizes e Bases da Educação Nacional, LDBEN 93/94, a educação escolar compõe-se de educação básica e educação superior. Uma das finalidades do ensino superior é "estimular a criação cultural e o desenvolvimento do espírito científico e do pensamento reflexivo" (BRASIL, 1996).

Ao tratar do ensino superior para pessoas com deficiência, a situação pode ser ainda mais complexa ao conhecer a história da Educação Especial (JANNUZZI, 2004; KASSAR, 2013). Deste modo, são poucos os que conseguem chegar ao ensino superior.

Quando o professor do ensino superior encontra um aluno com deficiência na sala de aula é importante ter a consciência de que houve muitas lutas no processo de escolarização. O estudo de Meletti e Bueno (2011) mostra que o atendimento ao aluno da educação especial no Brasil, no período de 1997 a 2006, se concentrou em espaços segregados, instituições e classes especiais, e que não apresenta uma tendência de terminalidade da Educação Básica.

Nesse direcionamento, chegar ao ensino superior significa ultrapassar muitas barreiras, dentre elas a história do direito negado, e preconceitos. Nesse contexto, o professor do ensino superior precisa se atentar e elencar algumas questões: Como ensinar? Qual atendimento educacional especializado favorecerá a permanência e o processo de ensino-aprendizagem? Para tanto, é indispensável um trabalho coletivo,

*E-mail: maicon.depieri@kroton.com.br 
envolvendo a coordenação do curso, alunos, professores, funcionários e instituição. A acessibilidade em todos os espaços, por exemplo, laboratórios, bibliotecas, banheiros, dentre outros é indispensável, porém a permanência e a apropriação do conhecimento advêm de um conjunto de práticas acadêmicas que compreendem a formação e atuação docente.

Assim, o objetivo deste estudo foi analisar o relato de experiência de um docente de graduação em enfermagem com duas alunas com deficiência.

\section{MATERIAL E MÉTODO}

Análise do relato de experiência de um professor na graduação em Enfermagem: $O$ encontro com duas alunas com deficiência

Este estudo consiste na análise de um relato de experiência vivenciado por um docente de Graduação em Enfermagem, no início de sua profissão, ao ministrar disciplinas básicas no curso. Para referir ao professor utilizaremos a letra L.

Lucas descreveu sua percepção sobre o que foi vivido e percebido na graduação de enfermagem na perspectiva da educação especial entre os anos de 2013 a 2015 em um município do norte do Paraná.

O presente relato aborda a experiência vivenciada pelo docente $L$, com duas alunas com deficiência, nas séries iniciais, da formação universitária de enfermagem. As duas alunas serão mencionadas pelas letras T e A.

T tinha 24 anos e apresentava a deficiência física. A tinha 21 anos e era surda.

\section{A formação docente}

L iniciou a sua formação com o curso técnico em enfermagem e começou o trabalho no setor de Unidade de Terapia Intensiva (UTI). Uma vez por mês participava de treinamentos nomeados "educação permanente em enfermagem". Durante esses treinamentos foi incentivado por uma enfermeira a iniciar a graduação em enfermagem.

Na vigência da graduação, em uma aula da disciplina de Didática Aplicada a Enfermagem, a professora responsável solicitou que a turma elaborasse um plano de aula e escolheu três planos para ministrar a aula preparada. Dentre eles, estava o plano de aula de Lucas, a partir disso começou a se interessar pela docência no ensino superior. 
L iniciou a graduação em enfermagem, em 2006, em uma universidade privada no Norte do Paraná, vindo a concluir o curso em dezembro de 2009. Atuava como enfermeiro em uma Unidade de Pronto Atendimento Médico, também como professor do curso técnico em enfermagem.

Desde a graduação $L$ tinha o desejo em lecionar por ter facilidade em compartilhar o conhecimento. Atuava como monitor de disciplinas profissionalizantes no curso, como exame físico. Na monitoria, auxiliava os alunos que tinham dificuldades em compreender algumas técnicas.

L relata que em sua graduação tinha um aluno com deficiência visual congênita e com cirurgia de transplante de córneas recuperou a visão e atualmente trabalha como enfermeiro em um hospital de grande porte em um município do Norte do Paraná.

\section{RESULTADOS E DISCUSSÃO}

\section{A docência no ensino superior e a educação especial}

Em setembro de $2013 \mathrm{~L}$ foi convidado à docência no curso de enfermagem na mesma Universidade em que concluiu a graduação. Assumiu a disciplina de anatomia e fisiologia. Nessa disciplina foi apresentando aos alunos as partes e funções dos diversos sistemas do corpo humano, muitos são os termos técnicos e científicos empregados para transmissão dos conhecimentos aos acadêmicos.

No primeiro dia de aula $L$ pediu aos alunos que se apresentassem e se deparou com uma aluna surda $(A)$, que se apresentou por meio de uma intérprete (colega de classe). A instituição estava finalizando o processo de contratação de uma intérprete para acompanhar a aluna durante o curso.

Durante o curso $L$ percebeu que $A$ não estava conseguindo acompanhar as aulas.

Nesse momento decidiu trazer a aluna para sentar-se na primeira carteira, bem próximo do quadro.

Utilizei como estratégia falar mais pausadamente, pois fui alertado pela colega de classe que a leitura labial ajudaria. Enfim, esse trabalho durou cerca de 3 semanas, até que foi finalizado o processo de contratação de uma intérprete pela instituição. Mesmo assim, a aluna me procurou juntamente com sua colega que a auxiliava informando que iria desistir do curso, pois não estava conseguindo aprender. (PROFESSOR L). 
O professor questionou os motivos que incentivavam $A$ a evadir do ensino superior de enfermagem. Indagou se era por que não estava compreendendo os conteúdos ou se existia algum outro empecilho. Para a sua surpresa a aluna respondeu que na sala de aula não era vista pelos colegas da classe, com exceção do professor e da colega intérprete voluntária. Segundo a aluna:

[...] eles sabem que faço leitura labial e que posso interagir com eles, também sei escrever, eles bem que podiam escrever bilhetes e assim conversaria com eles, então professor, gostaria de agradecer a atenção, mas vou desistir do curso. (ALUNA A).

"O estigma da inferioridade na relação com pessoas não deficientes acompanha e constitui o imaginário social e institucionaliza práticas sociais que segregam e marginalizam" (CAIADO; BERRIBILLE; SARAIVA, 2013, p.25).

Outra situação foi de uma aluna com deficiência física $(T)$, que não tinha 0 antebraço esquerdo, a preocupação dos docentes do curso era como essa aluna executaria as técnicas que são de competência do egresso de enfermagem. Houve restrições para o desenvolvimento de algumas técnicas, no entanto em outros procedimentos o seu processo de aprendizagem era semelhante ou ainda melhor que de seus pares.

Nesse contexto, Artioli (2006, p.121) afirma que

\begin{abstract}
Muitas vezes, a inclusão esbarra em questões que vão além do domínio de técnicas e práticas pedagógicas que podem ser desenvolvidas pelo professor em sala de aula. Na verdade, pode mesmo estar envolvida a ideia preconcebida de que a pessoa com deficiência tem uma incapacidade generalizada para aprender e conviver socialmente.
\end{abstract}

Dentre as habilidades e competências do enfermeiro está a realização de diversas técnicas com objetivo de contribuir para o processo do cuidar, mas esse também exerce papel de gestor em suas equipes. $\mathrm{O}$ corpo docente percebeu que a deficiência física apresentada pela aluna não seria uma barreira para permanecer e concluir o curso de enfermagem. T concluiu a graduação, especializou-se em Gestão em Saúde, Auditoria em Saúde e atualmente é enfermeira concursada em um município no norte do Paraná, atua na gestão de uma Unidade Básica de saúde, realiza palestras sobre diversos temas de competência da enfermagem, bem como sobre a inclusão de deficientes seja físico ou outras no curso de enfermagem. 
Estudos mostram que pessoas com deficiência se escolarizaram e que exercem profissões qualificadas apesar da negação de direitos, dentre eles a educação, às pessoas com deficiência.

Decidido a trabalhar como docente no ensino superior o professor fez formação continuada.

\begin{abstract}
Hoje sete anos após minha formação universitária, fiz três especializações, sendo a primeira em Urgência e Emergência em Enfermagem, a segunda em Gestão e Organização em Saúde e a terceira em Enfermagem em Cardiologia, pretendo me dedicar cada vez mais para contribuir e aumentar o acesso dos alunos com deficiências no curso de enfermagem. Cabe a nós, professores e equipe pedagógica, o envolvimento desse aluno no processo, facilitando a aprendizagem dos acadêmicos tidos como deficientes (PROFESSOR L).
\end{abstract}

Artioli (2006, p.121) afirma que a formação do professor é ao longo da vida e que é indispensável o conhecimento sobre a área da educação especial para que na ação docente não haja uma redução da pessoa com deficiência na incapacidade, ao contrário, deve-se focar as potencialidades a serem desenvolvidas.

\begin{abstract}
Destaco que sempre tive grandes preocupações e certa ansiedade em saber como inserir alunos com deficiência no ensino, e como minha formação é enfermagem, tenho comigo esse desejo de ter cada vez mais ingressantes no curso, mas tão importante quanto o acesso ao ensino superior, é a permanência, e conclusão do curso por parte desse aluno. (PROFESSOR L).
\end{abstract}

O encontro com as duas alunas com deficiência no superior suscitou questionamentos sobre a organização institucional para promover o acesso e permanência e sobre a prática pedagógica na sala de aula no intuito de ensinar os conteúdos e adaptar materiais para que as alunas tivessem sucesso no ensino superior. Deste modo, o relato mostrou que o professor $L$ se sentiu inquieto em um primeiro momento e posteriormente foi adequando as suas aulas para atender as alunas com deficiência. Verifica-se um comprometimento deste docente com a formação de suas alunas com deficiência.

\title{
CONCLUSÃO
}

Faz-se necessário uma discussão permanente acerca da formação dos professores em todos os cursos da graduação.

O curso de enfermagem forma bacharéis, sendo que muitos alunos às vezes não tem a perspectiva de exercer a docência, e a grade curricular apresenta disciplinas para a formação de professores de forma superficial. Para tanto, o (a) 
enfermeiro (a) que for trabalhar na docência necessitará de um preparo pedagógico para ensinar todos os alunos, com e sem deficiência. Além disso, a LDBEN (BRASIL, 1996) determina que formação dos professores que exercem o magistério no ensino superior deva ocorrer em cursos de pós-graduação, prioritariamente em mestrado e doutorado.

Conclui-se que, por um lado, a vinda dos alunos com deficiência para o ensino superior representa um avanço educacional no Brasil. Por outro, as instituições de ensino superior, assim como todas as instituições de educação básica, precisam apresentar uma proposta pedagógica concreta para possibilitar a apropriação dos conhecimentos científicos para o desempenho profissional desses sujeitos. O acesso ao ensino superior é o primeiro passo, seguido pela permanência e sucesso escolar para o recebimento do tão esperado diploma de graduado.

\section{REFERÊNCIAS}

ARTIOLI, A.L. A educação do aluno com deficiência na classe comum: a visão do professor. Psicologia da Educação, v.1, p.103-121, 2006.

BRASIL. Lei n 9.394, de 20 de dezembro de 1996. Estabelece as Diretrizes e Bases da Educação Nacional. 1996.1 Disponível em: <http://www.planalto.gov.br/ccivil_03/leis/L9394.htm>. Acesso em: 21 jul. 2016.

CAIADO, K.R.M.; BERRIBILLE, G. R.; SARAIVA, L. A. Educação e deficiência na voz de quem viveu essa trama. In: CAIADO, K.R.M. (Org.). Trajetórias escolares de alunos com deficiência. São Carlos: EDUFSCar, 2013, p.17-33.

JANNUZZI, G. A educação do deficiente no Brasil: dos primórdios ao início do século XXI. Campinas: Autores Associados, 2004.

KASSAR, M.C.M. Uma breve história da educação das pessoas com deficiências no Brasil. In: MELETTI, S.M.F.; KASSAR, M.C.M. (Org.). Escolarização de alunos com deficiências: desafios e possibilidades. Campinas: Mercado de Letras, 2013. p.3376.

MELETTI, S.M.F.; BUENO, J.G.S. O impacto das políticas públicas de escolarização de alunos com deficiência: uma análise dos indicadores sociais no Brasil. Linhas Críticas, v.17, p.367-384, 2011. 